\title{
Didáctica de las enseñanzas artísticas impartidas en las Facultades de Educación y Tecnologías de la Información y la Comunicación: la webquest como estrategia metodológica construccionista
}

\section{Didactics of art education taught in the Faculties of Education and Information Technologies and Communication: the webquest as a constructionist methodological strategy}

\author{
Pedro Victorio SAlido-López \\ Universidad de Castilla la Mancha \\ pedrov.salopez@gmail \\ Francisco MaEso-Rubio \\ Universidad de Granada \\ fmaeso@ugr.es
}

Recibido: 15 de enero de 2013

Aprobado: 16 de abril de 2013

\section{Resumen}

La sociedad actual se encuentra sumida en un proceso de cambio continuo que se ha visto favorecido, en gran parte, por los avances acaecidos en el mundo de las Tecnologías de la Información y la Comunicación (TIC's). Como no podía ser de otra manera, los profesionales de la educación han adoptado con más o menos éxito esta realidad del siglo XXI a su trabajo en la escuela. Tecnología e Internet, por tanto, han pasado a formar parte de las herramientas didácticas que numerosos docentes utilizan en el aula, causa principal del desarrollo de una metodología más activa en la que el verdadero protagonista es el alumnado.

En este caso, centraremos nuestra propuesta metodológica en el uso de la webquest como herramienta 2.0 para el desarrollo de un modelo enseñanza-aprendizaje construccionista aplicable a las enseñanzas artísticas impartidas en las Facultades de Educación. Este nuevo planteamiento en el aula no trata de sustituir las herramientas didácticas puestas en uso hasta el día de hoy. Más bien, su finalidad primordial es establecer unas competencias que permitan aunar tradición y 2.0 y adaptar la formación de los futuros maestros de Infantil y Primaria a las exigencias curriculares y sociales de mundo actual. Palabras clave: Didáctica, Educación Artística, Web 2.0, Webquest, Construccionismo.

Victorio Salido-López, P. Maeso Rubio, F. (2013) Didáctica de las enseñanzas artísticas impartidas en las Facultades de Educación y Tecnologías de la Información y la Comunicación: la webquest como estrategia metodológica construccionista. Arte, Individuo y Sociedad, 26 (1) 153-172 


\begin{abstract}
Our current society finds itself in a process of continuous change which has been favoured mostly by the advances happening in the world of Information and Communication Technology (TIC's).

Rightly, education professionals have adapted, failing or succeeding, this fact from the XXI century to their work in school. Therefore, Technology and Internet have become part of the didactic tools used by numerous teachers in their classrooms. This is the main cause of the development of a more active methodology in which the main role is played by students.

As it can be seen in this project, we will focus our methodological approach on the use of the webquest as a 2.0 tool with the purpose of developing a constructionist teaching-learning model applicable to the art education taught in the Faculties of Education.

This new approach which will be put into practice in the classroom can't be regarded as a way of replacing the current didactic tools but as a project whose main aim is to establish some skills which allow linking tradition and 2.0 as well as adapt the training of future teachers, who work with children aged between 3-11 years old, to the curricular and social demands of today's world.
\end{abstract}

Key words: Didactics, Arts Education, Web 2.0, Webquest, Constructionism.

Victorio Salido López, P. Maeso Rubio, F. (2013) Didactics of art education taught in the Faculties of Education and Information Technologies and Communication: the webquest as a constructionist methodological strategy. Arte, Individuo y Sociedad, 26 (1) 153-172

Sumario: 1. Introducción, 2. Definición de conceptos clave, 3. Imágenes clave, 4. Las Tecnologías de la Información y la Comunicación en Educación Superior: una propuesta de investigación 2.0 en enseñanzas artísticas, 4.1 Web 2.0 y Universidad: a propósito de la webquest, 4.2. Hipótesis de investigación y objetivos propuestos: enseñanzas artísticas y tecnología Web 2.0, 4.3. Metodología: la investigación-acción en educación, 4.4. ¿Herramientas 2.0 en Educación Plástica y Visual? Formulación, evaluación y resolución de webquest como estrategia de investigación, 4.5. Las posibilidades de la webquest en la formación del profesorado: ventajas e inconvenientes de su uso como herramienta didáctica, 4.6. La webquest en Educación Superior: competencias socioprofesionales para un uso adecuado en Educación Artística, 4.7. La alfabetización digital y no-digital del alumnado universitario a través de las posibilidades de la webquest, 5. Conclusiones. Referencias. Recursos impresos y electrónicos. URL's de interés. Anexo: rúbrica de evaluación de webquest.

\title{
1. Introducción
}

A lo largo de la historia de la humanidad todas las culturas han sentido una enorme inquietud por instruir a sus descendientes. Tanto es así que ya los pueblos primitivos, aún careciendo de maestros y teorías pedagógicas, educaban a sus hombres para desenvolverse y sobrevivir en una rudimentaria vida social en la que la creación artística también tuvo su cabida. Este interés por formarse y educarse se ha prolongado y ha evolucionado en el tiempo, encontrando diferentes prácticas metodológicas que han incluido actividades tan dispares como el viaje -véase del denominado Grand Tour, que se correspondía con un periplo por la Europa del siglo XVIII como experiencia de aprendizaje- o prácticas fundamentadas en las más novedosas tecnologías como medio de formación.

En este último contexto es el que nos vamos a mover en los siguientes apartados, pues de un tiempo a esta parte han sido numerosas las exigencias curriculares y sociales en relación con el dominio de las Tecnologías de la Información y Comunicación (TIC's). Los profesores, por tanto, deben ser capaces de acomodarse a los continuos cambios para formar mejor a los que en un futuro no muy lejano serán los profesio- 
nales de la educación. Pero, ¿están los docentes de hoy lo suficientemente preparados para explotar las posibilidades de las TIC's en educación y, en consecuencia, dar una formación adecuada a sus educandos? ¿Somos conscientes de las competencias que se han de dominar para dar respuesta a las necesidades educativas propias del siglo XXI? ¿En realidad las TIC's suponen una mejora en la formación y manera de aprender del individuo? ¿Es necesario olvidarnos de las herramientas y materiales didácticos puestos en uso hasta día de hoy ante un inminente triunfo de las Nuevas Tecnologías?

Estos interrogantes son la base de los desafíos a los que se están enfrentando día a día los profesionales de la educación. En este caso, intentaremos darles respuesta a través de uso de la webquest en las enseñanzas artísticas impartidas en la formación de los futuros profesionales de las etapas de Infantil y Primaria. Nuestro trabajo rema en la misma dirección de aquéllos que se han interesado por adaptar esta disciplina a la realidad y exigencias sociales del siglo XXI (Toro, 2011; Saura, 2011; entre otros), Educación Artística denominada por algunos estudiosos 3.0 (Saura, 2012) que ha sido causa del desarrollo nuevas actitudes en el aula.

\section{Definición de conceptos clave}

Didáctica: "La didáctica es la disciplina o tratado riguroso de estudio y fundamentación de la actividad de enseñanza, en cuanto que propicia el aprendizaje formativo de los estudiantes en los más diversos contextos" (Medina Rivilla y Salvador Mata, 2009: 7).

EduCACión Artística: "La Educación Artística es una forma de desarrollo de la sensibilidad que involucra un concepto amplio de cultura, ya que plantea interés por estimular las capacidades del individuo y de su grupo social para desarrollar las potencialidades creadoras, organizar la propia experiencia y ponerla en contacto con los otros. En ese sentido, esta educación debiera contemplarse desde marcos interpretativos interdisciplinarios que permitan ubicarla contextualmente tanto en los procesos históricos y culturales como en los aspectos cognitivos y sensitivos inherentes al individuo" (Elichiry y Regatky, 2010: 130).

Weв 2.0: concepto acuñado por Tim O'Really en 2004 para describir una segunda generación de contenidos web creados por los propios usuarios de Internet y puestos a disposición de los demás. Potencia espacios virtuales para la interacción social y la participación abierta basados en aplicaciones telemáticas intuitivas, gratuitas y fáciles de manejar (Cabero Almenara, López Meneses y Llorente Cejudo, 2009: 23-30).

WeBquest: Bernie Dodge desarrolló junto a Tom March el modelo webquest en 1995 como una publicación en la web, elaborada generalmente por el profesorado, con la finalidad de ofrecer al alumnado una guía eficiente y segura para desarrollar actividades de aprendizaje y de investigación sobre información y contenidos que, en gran parte, son accesibles a través de Internet (Dodge, 1995). Su estructura se orga- 
niza en torno a cinco apartados básicos: introducción, tarea, proceso y recursos, evaluación y conclusión (Temprano Sánchez, 2009: 15-16; Shweizer y Kossow, 2007).

ConstrucCionismo: el Construccionismo es una teoría pedagógica desarrollada por Seymour Papert, matemático y psicólogo discípulo de Jean Piaget. Su principal activo es la defensa de que el aprendizaje es más eficaz cuando es parte de una actividad que el sujeto experimenta como la construcción de un producto significativo. Tanto el Construccionismo como el Constructivismo, por tanto, plantean que el aprendizaje radica en una construcción interna y el conocimiento no se puede "comunicar manufacturado" -en palabras de Piaget-. Si bien, el Construccionismo le concede una especial importancia al papel que pueden desempeñar las construcciones en el mundo como apoyo a las que se producen en la cabeza del individuo, convirtiéndose así en una doctrina menos mentalista; además, se toma más en serio la idea de construcción mental al reconocer más de un tipo de construcción -"algunas tan alejadas de lo que solemos entender por construir como cultivar un jardín", dice Papert- y al preguntarse por los medios y materiales que se suelen utilizar para ello (Papert, 1995: 151-170; Ackermann, 2001).

\section{Imágenes clave}

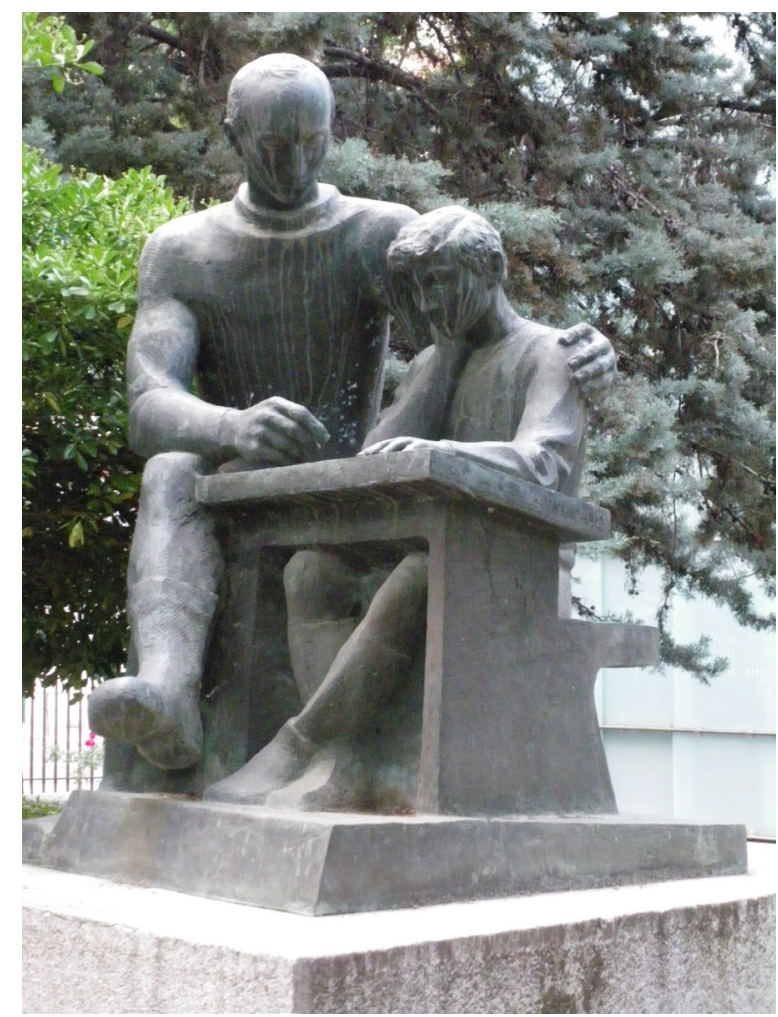

Figura 1. Profesor y alumno. Fotografía de autor sobre escultura anónima. 2012. 


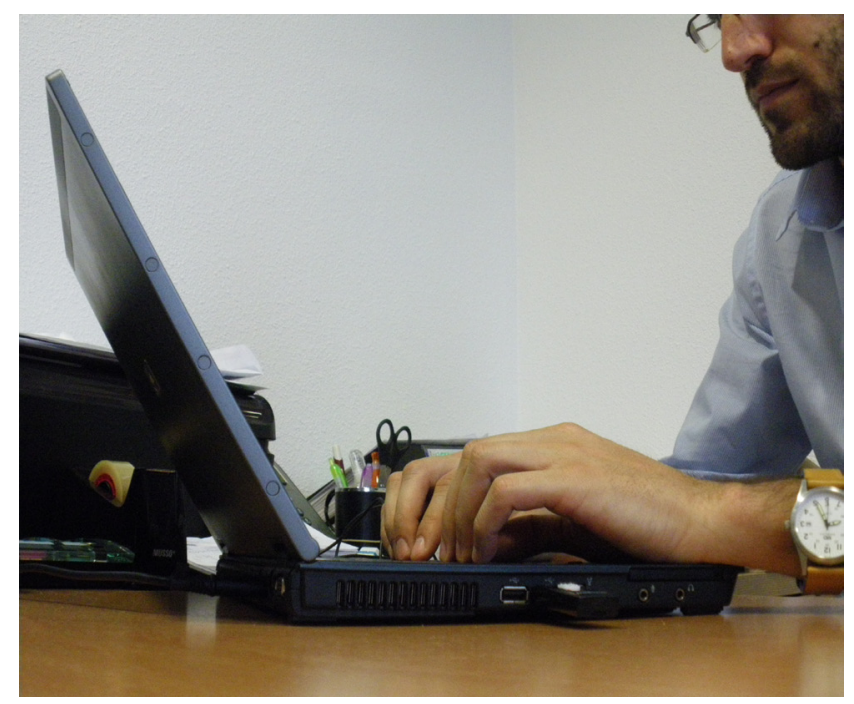

Figura 2. Profesor y alumno en el siglo XXI. Fotografía de autor. 2012.

\section{Las Tecnologías de la Información y la Comunicación en Educación Superior: una propuesta de investigación 2.0 en enseñanzas artísticas}

\subsection{Web 2.0 y Universidad: a propósito de la webquest}

Dado el mencionado protagonismo de las TIC's en la sociedad actual y las exigencias curriculares en torno al dominio de las mismas, no cabe duda de que el docente de cualquier disciplina y etapa educativa se ha visto obligado a desarrollar habilidades que le permitan explotarlas didácticamente hablando. Sobre este tema encontramos mucha literatura que, con mayor o menor fortuna, ha intentado dar solución a la introducción de las tecnologías en el aula, con el hándicap añadido de encontrarnos en un momento en el que un gran porcentaje del profesorado forma parte de una generación que los estudiosos actuales han dado en llamar "inmigrantes digitales" (Prensky, 2001: 1-6). Este colectivo docente, mayores de 35 años, se ha adaptado a la tecnología pero después de un esfuerzo y actualización de conocimientos que en ocasiones no ha dado el fruto deseado.

A nivel universitario, los desafíos del Espacio Europeo de Educación Superior (EEES) han sido la causa del desarrollo de un nuevo paradigma educativo. En este contexto, es apreciable una evolución desde la universidad de la enseñanza a un modelo en el que predomina un aprendizaje fundamentado en el dominio de unas competencias con un carácter construccionista muy claro y evidente.

En este contexto de innovación y aprendizaje por competencias, las TIC's han saltado a la palestra de la educación y han sorprendido a los profesionales por sus posibilidades para hacer al alumnado el verdadero protagonista de su formación. $\mathrm{Si}$ bien, es cierto que ha sido necesario un desarrollo bastante significativo en el concepto de Internet para que esto sea así, evolución que ha dado como resultado el con- 
cepto Web 2.0. Frente a la primera generación de publicaciones en la red de redes, el nuevo concepto Worl Wide Web se caracteriza por el lugar preeminente otorgado al propio usuario, pues le permite interactuar y ser, además de consumidor, productor de información virtual (Castaño Garrido, Maiz Olazabalaga, Palacio Arko y Villarroel Villamor, 2008: 61-63).

Entre las herramientas generadas por este concepto de Internet 2.0 destacan algunas como blogs, videoblogs, wikis, mapas conceptuales o webquest. Todas ellas han supuesto una nueva manera de comunicarse, formarse y aprender en un entorno virtual y colaborativo. En nuestro caso, y ante las preferencias del grupo de investigación, decidimos centrar nuestra labor en el análisis de la webquest como principio metodológico en la conocida Universidad 2.0. Esta herramienta, desarrollada por Bernie Dodge y Tom March en 1995, sigue el modelo ITO de Feuerdtein (Input, Transformation y Output) atendiendo a tres estadios de acto mental: recepción de información, transformación e información de salida (Temprano Sánchez, 2009: 18). Se caracteriza por ser una guía bastante eficaz para desarrollar actividades de aprendizaje y de investigación sobre contenidos que, en gran parte, son accesibles a través de Internet.

Partiendo de las principales aportaciones sobre esta herramienta 2.0 y de las posibilidades que ofrecen las plataformas de publicación de webquest en red, proponemos para el caso que nos ocupa la siguiente estructura:

- Introducción: se corresponde con la primera parte de la webquest y permite dar a usuario o lector una información general sobre el problema expuesto en los pasos siguientes, cómo se va a resolver y, sobre todo, debe despertar su interés para que el aprendizaje sea más constructivo.

- Objetivos: hacen referencia a las capacidades que el usuario debe alcanzar con la realización de la webquest. Son el punto de referencia para evaluar y valorar el proceso formativo que llevaremos a cabo con el uso de esta herramienta 2.0. En algunos casos, pueden aparecen formulados al final de la Introducción.

- Tarea: es el medio que vamos a utilizar para conseguir los objetivos planteados. Permite al usuario sintetizar, organizar y clasificar la información aportada en Internet y en diferentes publicaciones acreditadas sobre el tema a tratar. Por tanto, debe recoger preguntas fundamentadas en relación con los contenidos a estudiar.

- Proceso: debe recoger de forma bastante clara cómo se ha de resolver la tarea, la manera de organizar la información recabada o cómo se ha de distribuir el grupo de trabajo para que la resolución de la webquest sea lo más constructiva posible. Es fundamental aportar cuantos más datos mejor para que el usuario sepa en qué paso se encuentra y cuál es el siguiente. Además, debe dar a conocer el resultado final de su resolución - una presentación Power Point, un mapa conceptual, una creación audiovisual, una obra de Net.Art...-.

- Recursos on-line y material impreso: en este apartado se deben incluir los enlaces web o recursos que el autor considere necesarios para poder llevar a cabo la resolución de la webquest. Entre éstos, creemos necesario recoger, además de recursos electrónicos acreditados, material de biblioteca sobre el 
tema a tratar para trabajar habilidades que permitan al individuo alfabetizarse en el campo de la cultura impresa y no fomentar actitudes de sumisión ante las Nuevas Tecnologías, imágenes, vídeos, mapas conceptuales o cualquier otro material que permita llevar a cabo un proceso de aprendizaje constructivo. En ocasiones, este apartado de recursos aparece unido al proceso.

- Evaluación: debe dar a conocer los criterios cualitativos -siempre en relación directa con los objetivos a conseguir- y cuantitativos para que el usuario conozca qué se va a evaluar y cómo. De un tiempo a esta parte, se están usando rúbricas para este menester que, como es evidente, en una webquest también permiten implicar al usuario en su propio proceso de evaluación (Conde Rodríguez y Pozuelo Estrada, 2007; Temprano Sánchez, 2009: 40-42).

- Conclusión: es el punto y final de un proceso de aprendizaje constructivo $\mathrm{y}$, como tal, debe dar a conocer los principales logros conseguidos con la resolución. Además, debe abrir la puerta a la reflexión e intentar despertar la curiosidad para seguir investigando sobre el tema.

Las principales plataformas para la publicación de webquest en la red -véase, por ejemplo, phpwebquest o aula21- permiten, además, ilustrar visualmente cada uno de los apartados mencionados. Este hecho supone un valor añadido para esta herramienta didáctica, sobre todo en un momento en el que la imagen ha ganado terreno a la palabra y están demostradas sus posibilidades para llevar a cabo un aprendizaje significativo.

\subsection{Hipótesis de investigación y objetivos propuestos: enseñanzas artísticas y tecnología Web 2.0}

Tal y como ha quedado puesto de manifiesto en los apartados anteriores, el docente universitario debe adaptarse a ese concepto de innovación propio de la Sociedad del Conocimiento. En nuestro caso, la hipótesis de investigación para conseguir este reto parte de un planteamiento didáctico con webquest en la asignatura Educación Plástica y Visual, impartida en el tercer curso del Grado de Maestro en Educación Primaria de la Facultad de Educación de Ciudad Real (UCLM). El alumnado pertenece al colectivo de "nativos digitales", término acuñado por Marc Prensky para referirse a aquellos individuos que han nacido y crecido usando la red y que son menores de 30 años (Prensky, 2001). Las habilidades de éstos para dominar las TIC's son una ventaja para el desarrollo de propuestas como la descrita con el título mismo de este trabajo.

Por otro lado, cabe destacar que nuestra propuesta parte de la idea de que la Educación Artística no es una asignatura de manualidades, en contra de lo que piensa gran parte de la población. Si bien, es cierto que la creación artística es la base de esta disciplina y el método más común en cualquier nivel educativo. Sin embargo, hemos de tener presente la necesidad de trabajar otras herramientas para desarrollar contenidos teóricos en un contexto de construcción de conocimiento. En este sentido, Internet y la webquest pueden llegar a tener un papel muy relevante. 
Partiendo de esta idea, compartida con otros profesionales de la Educación Artística, los objetivos fijados para el desarrollo de este trabajo han sido los siguientes:

- Comprobar el potencial de Internet como recurso para impartir contenidos de didáctica de las enseñanzas artísticas en Educación Superior.

- Dar a conocer las principales ventajas e inconvenientes del uso de la webquest en educación a través de una propuesta en el aula de Educación Artística.

- Establecer las competencias profesionales para el manejo de las TIC's y, de manera concreta, para el uso de la webquest como herramienta didáctica.

- Comprobar los aportes de la webquest como herramienta educativa construccionista.

- Generar una rúbrica de evaluación de webquest válida para su uso en cualquier nivel educativo.

- Investigar las líneas de actuación para la alfabetización digital del alumnado universitario a través de la formulación de webquest sobre contenidos artísticos.

\subsection{Metodología: la investigación-acción en educación}

Conseguir los objetivos planteados en esta propuesta de investigación pasa por la elección de una metodología que permita comprobar los problemas que día a día experimenta el profesor en el aula en relación con el uso de la Web 2.0 y, a partir de ahí, actuar en consecuencia para mejorar la práctica docente. Evidentemente, este proceso se enriquece cuando a la opinión del investigador y observador principal se suman las experiencias de otros profesionales y, sobre todo, de los alumnos y alumnas como principales protagonistas del aprendizaje (Latorre, 2008: 5-6). De ahí que una propuesta metodológica de investigación-acción en educación se ajuste perfectamente a los objetivos planteados, aunque en ocasiones sea necesario orientarnos por los principios actuación de los estudios de casos.

La investigación-acción es uno de los enfoques metodológicos propios de las ciencias humanas y sociales, y forma parte de los principales métodos de investigación en Educación Artística -Art Education Research- (Marín, 2003: 465). Su origen se encuentra en las prácticas del psicólogo social Kurt Lewin, que acuñó este término en la década de los cuarenta del siglo XX para referirse a una forma de indagación con grupos o comunidades cuya finalidad era modificar sus circunstancias personales y sociales para conseguir el bien común (Suárez Pazos, 2002: 40). En educación cobró protagonismo con los trabajos de Wilfred Carr y Stephen Kemmis (1988), los de John Elliott (1990 / 2010) o los de Pamela Lomax (1995), que intentaron definir esta manera de intervención en la que el profesional hace uso en su práctica de la función investigadora para intentar mejorar la calidad de la enseñanzaDe todas las aportaciones sobre las características de este enfoque metodológico, vamos a dar a conocer las fijadas por Lomax (1995: 51), para quien la investigación-acción presenta seis rasgos fundamentales: 
- Trata de mejorar la práctica educativa a través de la intervención.

- Implica al investigador como foco principal de la investigación.

- Es participativa e implica a los demás como co-investigadores -supone, por tanto, la participación de otros profesionales-.

- Es una forma rigurosa de indagación que lleva a generar teoría en la práctica.

- Necesita una continua validación de testigos educativos desde el contexto al que sirve.

- Es una forma pública de indagación.

\section{4. ¿Herramientas 2.0 en Educación Plástica y Visual? Formulación, evaluación y resolución de webquest como estrategia de investigación}

El punto de partida para conseguir los objetivos propuestos en la hipótesis de investigación fue la introducción al alumnado participante en la investigación al concepto Web $2.0 \mathrm{y}$, concretamente, al de webquest como método de aprendizaje en la Sociedad del Conocimiento. A partir de ahí, fue fundamental estructurar el trabajo en el aula en tres fases -formulación, evaluación y resolución webquest- que permitieron establecer una serie de ventajas e inconvenientes sobre el uso de esta metodología construccionista en educación formal y, a su vez, formular una rúbrica que permitiera valorar el nivel de calidad de este tipo de herramientas didácticas.

La primera fase, relativa a la formulación de webquest por parte de un alumnado que adoptó el papel de docente, parte de la idea comúnmente admitida de que el diseñador debe dominar el tema a trabajar para poder realizar una propuesta solvente (Correa Gorospe, 2004). Para ello, se les facilitó el material necesario sobre parte de los contenidos de la asignatura Educación Plástica y Visual titulado El juego y la Educación Artística. Además, por trabajar una actividad en la que gran parte de los contenidos son accesibles a través de Internet, fue necesario seguir alfabetizando digitalmente al alumnado, dándoles a conocer los trucos de los principales buscadores en la red (véase la aportación al respecto en Saura Pérez, 2011: 144). Por otra parte, se empezaron a trabajar habilidades que les permitieran seleccionar la ingente cantidad de información accesible a través de Internet y hacer una crítica constructiva de la misma, destrezas necesarias para explotar de manera adecuada las posibilidades que la red ofrece didácticamente hablando. En este contexto de trabajo se detectaron importantes problemas para hacer un uso ético de la información, por lo que también fue necesario recordar en clase las normas de citas de la American Psychological Association.

La segunda fase está relacionada con la valoración de las webquest diseñadas por el grupo de investigación en un momento inmediatamente anterior. Para ello, se atendió a una rúbrica de evaluación basada en los errores detectados en la fase de formulación -reflejados en los niveles de calidad bajo y medio- y en las mejoras a incluir para conseguir un rendimiento óptimo de la herramienta 2.0 en el aula -nivel de calidad excelente- (véase el anexo final). En este momento se volvió a poner en práctica el proceso iniciado en la primera fase, con la finalidad de comprobar si las herramientas diseñadas por cada grupo de investigación cumplían los parámetros de excelencia marcados en la guía de evaluación facilitada. Los resultados de este se- 
gundo estadio de intervención en el aula evidenciaron los beneficios del sistema de evaluación con rúbricas, pues permite que sea el propio alumnado el que detecte los errores cometidos en su trabajo y actúe en consecuencia para mejorar su aprendizaje. En nuestro caso, esta labor de mejora se llevó a cabo reformulando la propuesta de webquest realizada en la fase primera.

La tercera fase, relativa a la resolución de las webquest realizadas por los propios alumnos y alumnas, evidenció las posibilidades que esta herramienta 2.0 ofrece para llevar a cabo un aprendizaje construccionista en el que el individuo a formar es el verdadero protagonista del proceso didáctico. La necesidad de transformar la información ofrecida por Internet en conocimiento evidenció el desarrollo de un pensamiento crítico y creativo para resolver problemas que pueden ir más allá de lo puramente artístico. Por su parte, el perfil de educador instructor propio de las metodologías clásicas se transformó en docente mediador y facilitador de aprendizaje, nuevo rol de profesor asociado a este modelo tecnológico y acorde con la realidad de la enseñanza del siglo XXI.

\subsection{Las posibilidades de la webquest en la formación del profesorado: ventajas e inconvenientes de su uso como herramienta didáctica}

El planteamiento metodológico de investigación-acción nos permitió fijar algunas de las ventajas e inconvenientes del uso de este tipo de herramientas 2.0 en el aula. Los resultados de las diferentes puestas en común del grupo de investigación fueron los siguientes:

\section{Ventajas}

$\checkmark$ Alta motivación y participación cooperativa.

$\checkmark$ El alumnado es un sujeto activo en la construcción de su conocimiento y su uso facilita los aprendizajes significativos.

$\checkmark$ Planteamiento cognoscitivo basado en la práctica.

$\checkmark$ Fuentes de información variadas y de rápida consulta.

$\checkmark$ Permite desarrollar un pensamiento crítico y creativo.

$\checkmark$ Se fomentan capacidades tecnológicas válidas para resolver cualquier problema no necesariamente artístico.

$\checkmark$ Facilita la comunicación con otras personas interesadas en el mismo tema.

$\checkmark$ El uso necesario de la imagen posibilita el desarrollo de la memoria visual.

$\checkmark$ Permite al alumnado "aprender a aprender".

$\checkmark$ Aleja la monotonía de la tradicional clase magistral. 


\section{Inconvenientes}

$\checkmark$ Los docentes en ocasiones se muestran reticentes a su uso en el aula.

$\checkmark$ Se genera mucha inseguridad en el grupo ante lo desconocido.

$\checkmark$ Se precisa de una formación permanente para controlar todo lo que supone Internet a la educación del siglo XXI.

$\checkmark$ En ocasiones genera una actitud pasiva y limitada a reproducir la información que ofrece Internet.

$\checkmark$ Exceso de información y en muchas ocasiones errónea.

$\checkmark$ La necesidad de usar Internet es causa de distracción para los alumnos y alumnas.

$\checkmark \quad$ Necesidad de alfabetización digital de los usuarios para darle un uso didáctico correcto.

$\checkmark$ Necesidad de registro o dificultades de uso de las principales plataformas de publicación de webquest en Internet.

\subsection{La webquest en Educación Superior: competencias socio-profesionales para un uso adecuado en Educación Artística}

Una vez dadas a conocer las ventajas e inconvenientes del uso de Internet y la webquest como recurso didáctico, comenzamos a trabajar en la redacción de diferentes competencias socio-profesionales que supusieran un nuevo concepto de profesor como medidor, así como un nuevo modelo de aprendizaje basado en la autonomía del alumnado para construir su propio conocimiento. El dominio de estas capacidades cognitivas, técnicas, actitudinales y éticas permitirá mejorar la práctica docente a nivel universitario y formar profesionales de la educación acordes con la realidad del siglo XXI. No obstante, hemos de tener en cuenta que estas competencias no apartan de la palestra de la educación las metodologías de enseñanza-aprendizaje puestas en uso hasta el día de hoy en Educación Artística; más bien, sirven de complemento a las mismas y permiten aunar tradición y vanguardia didácticamente hablando.

\section{Competencias cognitivas}

$\checkmark$ Conocer las exigencias del EEES en relación con las Nuevas Tecnologías para materializarlas con éxito en el aula.

$\checkmark$ Conocer los planteamientos y herramientas didácticas tradicionales en Educación Plástica y Visual para adaptarlos a las exigencias curriculares y sociales del siglo XXI.

$\checkmark$ Conocer principios metodológicos que favorezcan el desarrollo de capacidades estéticas, creativas y expresivas del alumnado a través de los recursos que ofrece Internet.

$\checkmark$ Poseer los conocimientos necesarios para adaptar la formulación de webquest a las exigencias didácticas de cada etapa educativa y disciplina a la que se refiera.

$\checkmark$ Conocer las principales ventajas e inconvenientes del uso de la webquest 
en Educación Superior para obtener un rendimiento óptimo de su uso en el aula.

$\checkmark$ Conocer la manera de aprovechar las posibilidades construccionistas y para generar aprendizajes significativos que ofrece la webquest.

$\checkmark$ Ser conscientes de la importancia y beneficios didácticos de ilustrar visualmente cada momento de un planteamiento didáctico basado en la webquest y actuar en consecuencia.

$\checkmark$ Conocer las principales normas de citas textuales y visuales para hacer un uso ético de la información.

\section{Competencias técnicas}

$\checkmark$ Tener un manejo de las TIC's para su uso en el aula.

$\checkmark$ Desarrollar habilidades para planificar actividades con planteamientos construccionistas y que relacionen herramientas y recursos didácticos 2.0 con materiales tradicionales -sobre todo de biblioteca-.

$\checkmark$ Dominar habilidades que permitan buscar, seleccionar y hacer una crítica coherente de la información que ofrece Internet como material didáctico y fuente de investigación.

$\checkmark$ Poseer destrezas que permitan aprovechar las posibilidades de trabajo colaborativo que ofrece la webquest.

$\checkmark$ Dominar habilidades para explotar las ventajas de trabajar con alumnado perteneciente a la generación de "nativos digitales" y obtener un rendimiento didáctico óptimo de la web 2.0.

\section{Competencias actitudinales y éticas}

$\checkmark$ Poseer una actitud positiva ante la innovación educativa y el desarrollo de nuevos espacios de educación.

$\checkmark$ Demostrar una actitud favorable ante la necesidad de reciclarse en TIC's para adaptar el trabajo en el aula a las exigencias curriculares actuales.

$\checkmark$ Valorar la importancia de formar individuos en TIC's para que sean capaces de resolver situaciones que van más allá de lo puramente artístico.

$\checkmark$ Fomentar las posibilidades de interacción social y colaboración entre iguales que ofrece la Internet y la webquest.

$\checkmark$ Demostrar un compromiso ético ante el uso de las fuentes.

$\checkmark$ Fomentar normas que permitan la formación de futuros maestros ni tecnófobos ni esclavos de las Nuevas Tecnologías.

$\checkmark$ Mostrar valores y actitudes que inciten a participar de manera activa en la adaptación de la Educación Artística a la realidad del siglo XXI.

$\checkmark$ Aceptar positivamente en nuevo rol de profesor como guía de aprendizaje. 


\subsection{La alfabetización digital y no-digital del alumnado universitario a través de las posibilidades de la webquest}

Si tenemos en cuenta las competencias profesionales expuestas en el apartado anterior, y concretamente la defensa de aunar tradición y vanguardia didácticamente hablando, cuando nos referimos a la alfabetización digital del alumnado a través del uso de la webquest hemos de fijar diferentes líneas de actuación. Los principales estudiosos sobre este concepto de alfabetización de individuos ante las exigencias de la sociedad del siglo XXI aluden a varios estadios de formación (Cabero Almenara, López Meneses y Llorente Cejudo, 2009: 61):

- Alfabetización en lectoescritura y cultura impresa: este punto de alfabetización se corresponde con el desarrollo de capacidades que permitan dominar la comunicación escrita y ser conscientes de todo lo que supone en la formación del individuo. En nuestro caso, la hemos abordado a través de la necesidad de hacer uso de los materiales de biblioteca como medio para contrastar la validez de la información facilitada por la red de redes. Este nivel de alfabetización permitirá seguir utilizando las herramientas didácticas puestas en uso hasta el día de hoy para desarrollar la parte más teórica de las enseñanzas artísticas -concretamente el uso de las publicaciones impresas más relevantes sobre esta disciplina-. Además, exige dar a conocer al alumnado las principales normas de citas textuales para hacer un uso ético de la información.

- Alfabetización en tecnologías y cultura digital: este estadio de la formación del futuro profesional de la educación hace referencia al desarrollo de conocimientos y habilidades digitales propiamente dichas. El uso de la tecnología Web 2.0 exige conocer y saber utilizar tanto el hardware como el software más relevante para poder llevar a cabo el diseño de herramientas válidas y explotar las posibilidades que ofrecen para el trabajo en el aula. Además, este nivel de alfabetización se corresponde con el desarrollo de capacidades para publicar en la red y comunicarse con iguales a través de las posibilidades que ofrece Internet.

- Alfabetización en lenguaje y cultura audiovisual: este estadio de alfabetización hace referencia al dominio de las principales formas comunicativas y expresivas del lenguaje audiovisual. En nuestro proceso de investigación en el aula hubo grupos de trabajo que hicieron uso del vídeo como recurso para resolver la tarea fijada en su webquest. Además, en algunos casos se propuso que el resultado de la webquest fuese creación audiovisual, aspecto éste que exige el conocimiento de los procesos, técnicas y recursos necesarios para que el producto final tenga éxito didácticamente hablando. De la misma manera que en la alfabetización en cultura impresa, es necesario desarrollar en el alumnado las habilidades necesarias para hacer un uso correcto de las citas visuales.

- Alfabetización informacional: este último paso se relaciona con el desarrollo de conocimientos y destrezas que permitan buscar información impresa, audiovisual o digital válida para conseguir los objetivos fijados con el diseño de 
la webquest. Tal y como ha quedado puesto de manifiesto páginas atrás, y de manera más explícita en la rúbrica de evaluación, el apartado de recursos es uno de los más importantes, pues de la validez de éstos depende que el resultado constructivo de la webquest sea el deseado.

\section{Conclusión}

Llegados a este punto, sólo queda retomar a modo de cierre todo lo tratado a lo largo del proceso de investigación. Una de las primeras conclusiones que podemos extraer se relaciona con el potencial que tiene Internet como herramienta didáctica. La red de redes ha evolucionado hacia un nuevo concepto en el que el internauta es consumidor y productor de información a la vez. He aquí el origen de la entrada en escena de aplicaciones web -webquest, blog, wikis...- propicias para llevar a cabo metodologías docentes construccionistas en cualquier disciplina y etapa educativa. No obstante, la facilidad que ofrece Internet para publicar información y ponerla al servicio de los demás exige un mínimo de espíritu crítico a la hora de buscar y hacer una selección exhaustiva de los contenidos accesibles de manera virtual, pues no todos son válidos. Como ha quedado puesto de manifiesto, junto a los recursos electrónicos acreditados sobre el tema a tratar, esta labor puede requerir el uso de publicaciones impresas que forman parte de los fondos bibliotecarios de la mayoría de universidades. Es evidente que esta manera de actuar en el aula exige hacer conocer las principales normas de citas textuales y visuales de cara a la necesidad de hacer un uso ético de la información.

Esta finalidad didáctica y de investigación otorgada a Internet la hemos vinculado a la formulación, evaluación y resolución de webquest. Los resultados obtenidos nos permiten concluir señalando las posibilidades que esta herramienta ofrece para que el alumnado sea el verdadero protagonista de su proceso formativo. Mientras, el profesor adopta el rol de guía fundamental y facilitador de conocimiento. No obstante, no todas las webquest publicadas en Internet sirven para conseguir estos objetivos. He aquí la necesidad de servirnos de algún método de evaluación de la calidad de estas aplicaciones 2.0 como la rúbrica recogida en el anexo.

En lo que atañe al uso de estas herramientas tecnológicas en el aula, cabe destacar a modo de conclusión que su puesta en práctica puede ser causa de una pérdida de tiempo y de un mal ejercicio didáctico por diferentes factores que van desde el desconocimiento técnico a la carencia de habilidades que permitan adaptarlas a las exigencias del grupo-aula. De ahí la necesidad de seguir trabajando para formar a futuros profesiones de la educación que sean capaces de sacar el máximo partido didáctico a las Nuevas Tecnologías, y se comprometan con una constante formación en sintonía con los cambios propios de la sociedad del siglo XXI.

Esta formación de profesionales de la educación en un contexto TIC exige, además, el dominio de unas competencias cognitivas, técnicas y actitudinales que garanticen un uso válido de este tipo de herramientas. Como es evidente, trabajar un campo caracterizado por el constante cambio hace de las competencias expuestas en las páginas anteriores una lista abierta y variable según la evolución de las Nuevas 
Tecnologías. De esta manera, estaremos comprometidos con un proceso de formación continuo para desarrollar un modelo de docente TIC, alejado del concepto tradicional de profesor usuario de metodologías vinculadas a la clase magistral y, en nuestro caso, capaz de avanzar para "[...] enseñar las artes visuales desde una perspectiva crítica y construccionista" (Maeso Rubio, 2008: 129-152).

La puesta en práctica de estas competencias docentes en Educación Superior permitirá, por otra parte, alfabetizar digitalmente a los futuros profesionales de la educación, pero sin olvidar esa vertiente de lectoescritura y cultura impresa a la que hacíamos referencia en el desarrollo del artículo. Sólo así, estaremos fomentado una actividad en el aula caracterizada por la motivación, el construccionismo, la creatividad, el cooperativismo, la posibilidad de uso de fuentes diversas y al alcance de todos, la comunicación virtual con otras personas interesadas en el tema y el espíritu crítico ante la realidad de la enseñanza de la segunda década del siglo XXI.

\section{Referencias}

\section{Recursos impresos y electrónicos}

Ackermann, E. (2001). Piaget's Constructivism, Papert's Constructionism: What's the difference? Future of learning group publication, 5 (3). [En línea] < http:// learning.media.mit.edu/content/publications/EA.Piaget\%20_\%20Papert.pdf $>$ (20-04-2012).

Cabero Almenara, J., López Meneses, E. Y Llorente Cejudo, Ma C. (2009). La docencia universitaria y las tecnologías web 2.0. Renovación e innovación en el espacio europeo. Sevilla: Mergablum.

Carr, W. Y Kemmis, S. (1988). Teoría crítica de la enseñanza: la investigación-acción en la formación del profesorado. Barcelona: Martínez Roca.

Castaño Garrido, C., Maiz Olazabalaga, I., Palacio Arko, G. J. Y Villarroel Villamor, J. D. (2008). Prácticas educativas en entornos WEB 2.0. Madrid: Síntesis.

Conde Rodríguez, A. Y Pozuelo Estrada, F. J. (2007). Las plantillas de evaluación (rúbrica) como instrumento para la evaluación. Un estudio de caso en el marco de la reforma de la enseñanza universitaria en el EEES. Investigación en la Escuela, 63: 77-90.

Correa Gorospe J. M. (2004). El webquest en la enseñanza universitaria: una experiencia en la formación inicial del profesorado. Qurriculum, 17: 171-186.

Dodge, B. (1995). WebQuests: a technique for Internet-based learning. Distance Educator, 1 (2): 10-13.

Elichiry, N. E. Y Regatky, M. (2010). Aproximación a la Educación Artística en la escuela. Anuario investigaciones, 17. Ciudad Autónoma de Buenos Aires. Ene/ dic.: $129-134$.

Elliot, J. (2010). La investigación-acción en educación (6 $6^{\mathrm{a}}$ ed). Madrid: Morata.

Latorre, A. (2008). La investigación-acción. Conocer y cambiar la práctica educativa. Barcelona: Graó.

Lomax, P. (1995). Action research for professional practice. British Journal of InService Education, 21 (19): 49-57. doi: 10.1080/0305763950210105. 
Maeso Rubio, F. (2008). Aprender a enseñar las artes visuales desde una perspectiva crítica y construccionista. En F. Maeso Rubio (coord.). El arte de enseñar el arte. Metodología innovadora en Bellas Artes (pp. 129-152). Sevilla: Diferencia.

Marín Viadel, R. (2003). Buscar y encontrar. La investigación en educación artística. En R. Marín Viadel (coord.). Didáctica de la educación artística (pp. 447-498). Madrid: Pearson.

Medina Rivilla, A. Y Salvador Mata, F. (coords.) (2009). Didáctica general. (2 ed.). Madrid: Pearson.

Papert, S. (1995). La máquina de los niños: replantearse la educación en la era de los ordenadores. Barcelona: Paidós.

Prensky, M. (2001). Digital Natives, Digital Immigrants. On the Horizon, 9 (5). October: $1-6$.

Saura Pérez, Á. (2011). Innovación educativa con TIC en Educación Artística, Plástica y Visual. Sevilla: MAD. (2012). E@: Educación Artística 3.0. Eari, 3: 77-86.

Suárez Pazos, M. (2002). Algunas reflexiones sobre la investigación-acción colaboradora en educación. En Revista Electrónica de Enseñanza de las Ciencias, 1, (1): 40-56 [En línea] < http://reec.uvigo.es/volumenes/volumen1/numero1/art3. pdf (04-04-2012).

Temprano Sánchez, A. (2009). Webquest: aproximación práctica al uso de Internet en el aula. Sevilla: Mad.

Toro, P. (2011): Los recursos de Internet como estrategia de enseñanza y aprendizaje en la Educación Plástica y Visual. Tesis Doctoral. Dirigida por el Dr. Eugenio Bargueño Gómez. UCM. [En línea] <http://eprints.ucm.es/12676/1/T32881.pdf> (10-02-2012).

\section{Recursos en Internet}

http://blog.educastur.es/luciaag/ (Consulta: 03-06-2012).

http://espiralcromatica.wordpress.com/about/ (Consulta: 03-06-2012).

http://phpwebquest.org/newphp/procesa_index_todas.php (Consulta: 03-06-2012).

http://www.aula21.net/Wqfacil/webquest.htm (Consulta: 03-06-2012). 


\section{Anexo I: algunas plataformas para crear webquest}

PHPWEBQUEST: aplicación diseñada en PHP por Antonio Temprano. Permite formular y resolver webquest, miniquest y cazas del tesoro sin la necesidad de usar programas de edición de páginas web.

Ejemplo de webquest en esta plataforma:

Pedro. El color. WQ [En línea] $<$ http:// edtk.co/01e9n> (Consulta: 22-03-2013)

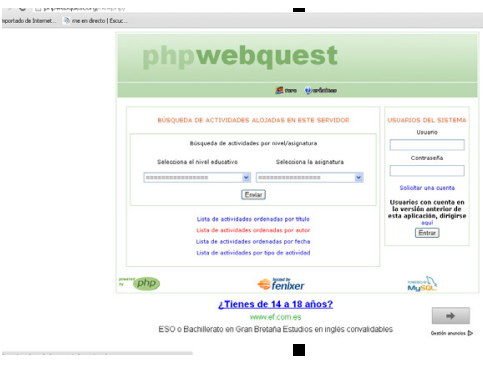

PVSL. Pantalla de inicio de phpwebquest. Captura de pantalla. 2013.

1, 2, 3 TU WEBQUEST. AULA 21: generador on-line de webquest diseñado y administrado por Francisco Muñoz de la Peña Castrillo. En su web, podemos encontrar numerosos recursos didácticos en un contexto TIC. forma:

Ejemplo de webquest en esta plata-

Francisco Muñoz de la Peña Castrillo. ¿Cómo nos ven los hijos de la Gran Bretaña? WQ [En línea] <http://edtk. co/8Fm6A> (Consulta: 22-03-2013).

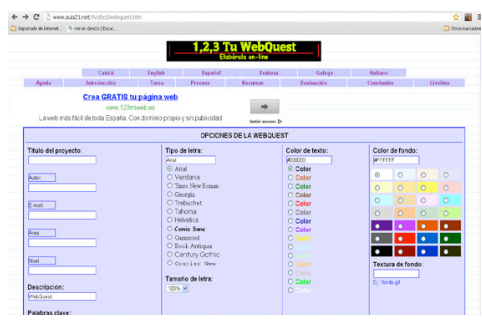

PVSL. Pantalla de inicio de phpwebquest. Captura de pantalla. 2013.
ZUNAL. COM: permite crear webquest on-line sin necesidad de utilizar códigos HTML. En inglés.

Ejemplo de webquest: G. BruderWerner. Cubism Modern Art Movement. WQ [En línea] < http://edtk.co/VEKHz> (Consulta: 22-03-2013).

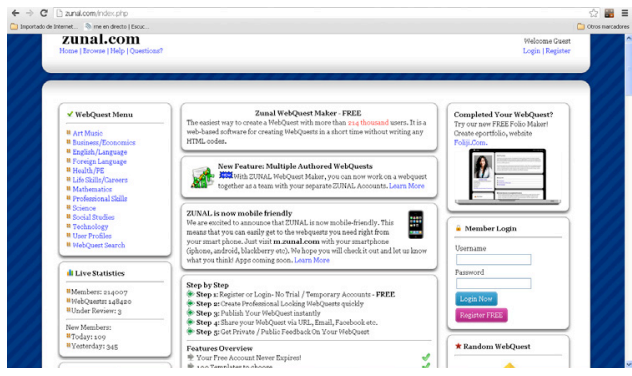

PVSL. Pantalla de inicio de zunal.com. Captura de pantalla. 2013

\section{Otras plataformas webquest}

CREADOR DE WEBQUEST CATEDU: portal del Centro Aragonés de Tecnologías para la Educación que permite crear webquest de una manera sencilla y si necesidad de dominios informáticos sofisticados $<\mathrm{http}$ ://catedu.es/ crear_wq/z_usuarios/ingreso_usuarios. php> (Consulta: 22-03-2013).

WEBQUES. ES: portal de Silvia Martínez Méndez para crear webquest o caza del tesoro on-line. Entre otras cosas, permite incluir enlaces a webquest creadas y alojadas en otros servidores o en la misma plataforma $<\mathrm{http}: / / \mathrm{www}$. webquest.es/crear-webquest-o-caza-deltesoro-online> (Consulta: 22-03-2013). 


\section{Anexo II: rúbrica de evaluación de webquest}

\begin{tabular}{|c|c|c|c|c|c|}
\hline \multicolumn{6}{|c|}{ NIVELES DE CALIDAD E ITEMS DE VALORACIÓN } \\
\hline & $\begin{array}{c}\text { BAJO } \\
0-2 \text { puntos }\end{array}$ & & $\begin{array}{c}\text { MEDIO } \\
\text { 2-4 puntos }\end{array}$ & & $\begin{array}{c}\text { EXCELENTE } \\
4-5 \text { puntos }\end{array}$ \\
\hline \multicolumn{6}{|c|}{ Introducción } \\
\hline $\begin{array}{l}\checkmark \\
\\
\checkmark \\
\checkmark \\
\checkmark\end{array}$ & $\begin{array}{l}\text { Tiene un planteamiento } \\
\text { formal y la información } \\
\text { que presenta no resulta } \\
\text { interesante. } \\
\text { No prepara al usuario para } \\
\text { el tema a tratar. } \\
\text { No anticipa ningún dato } \\
\text { metodológico de interés. }\end{array}$ & $\begin{array}{l}\checkmark \\
\checkmark\end{array}$ & $\begin{array}{l}\text { Anticipa al usuario en el tema } \\
\text { a tratar, pero no da a conocer } \\
\text { ningún dato motivador que } \\
\text { lo predisponga a una actitud } \\
\text { positiva. } \\
\text { Anticipa algún dato } \\
\text { metodológico, pero no tiene } \\
\text { en cuenta los conocimientos } \\
\text { previos del usuario. }\end{array}$ & $\begin{array}{l}\checkmark \\
\checkmark \\
\checkmark\end{array}$ & $\begin{array}{l}\text { Ofrece los datos } \\
\text { necesarios para motivar } \\
\text { al usuario y predisponerlo } \\
\text { positivamente para el } \\
\text { tema a tratar -incluidas } \\
\text { definiciones de los términos } \\
\text { más confusos-. } \\
\text { Lanza una pregunta con } \\
\text { carácter general y anticipa } \\
\text { cómo la vamos a resolver. }\end{array}$ \\
\hline \multicolumn{6}{|c|}{ Objetivos } \\
\hline $\begin{array}{l}\checkmark \\
\checkmark \\
\checkmark\end{array}$ & $\begin{array}{l}\text { Los objetivos de } \\
\text { aprendizaje no se formulan } \\
\text { de manera correcta. } \\
\text { Los objetivos no se } \\
\text { relacionan de manera } \\
\text { directa con el tema. }\end{array}$ & $\begin{array}{l}\checkmark \\
\checkmark\end{array}$ & $\begin{array}{l}\text { Los objetivos se formulan de } \\
\text { manera correcta. } \\
\text { Los objetivos se relacionan } \\
\text { con los contenidos a tratar, } \\
\text { pero son insuficientes. }\end{array}$ & & $\begin{array}{l}\text { Los objetivos se formulan } \\
\text { de manera correcta. } \\
\text { La consecución de todos } \\
\text { los objetivos planteados } \\
\text { permite dominar los } \\
\text { contenidos del tema a tratar. }\end{array}$ \\
\hline \multicolumn{6}{|c|}{ Tarea } \\
\hline $\begin{array}{l}\checkmark \\
\\
\\
\checkmark \\
\checkmark\end{array}$ & $\begin{array}{l}\text { La tarea no permite } \\
\text { conseguir los objetivos de } \\
\text { aprendizaje propuestos ni } \\
\text { da a conocer el producto } \\
\text { final. } \\
\text { La tarea no se relaciona } \\
\text { directamente con } \\
\text { los contenidos de la } \\
\text { investigación propuesta. } \\
\text { La tarea no exige el uso } \\
\text { de fuentes distintas a la } \\
\text { wikipedia o semejantes. } \\
\text { Es demasiado genérica y no } \\
\text { exige de un pensamiento } \\
\text { crítico. }\end{array}$ & & $\begin{array}{l}\text { La tarea propuesta se } \\
\text { relaciona con los objetivos y } \\
\text { contenidos propuestos, pero es } \\
\text { insuficiente. } \\
\text { La tarea planteada no está } \\
\text { graduada en dificultad ni se } \\
\text { plantea de manera deductiva. } \\
\text { La tarea exige el uso de } \\
\text { diferentes fuentes virtuales, } \\
\text { pero no obliga a hacer un uso } \\
\text { de los clásicos sobre el tema a } \\
\text { investigar. }\end{array}$ & & $\begin{array}{l}\text { La tarea permite conseguir } \\
\text { de manera eficiente los } \\
\text { objetivos propuestos. } \\
\text { La tarea se relaciona con } \\
\text { todos los contenidos a } \\
\text { investigar. } \\
\text { La tarea exige el uso de } \\
\text { fuentes virtuales y de las } \\
\text { principales publicaciones } \\
\text { impresas sobre el tema } \\
\text { propuesto. } \\
\text { La tarea propuesta permite } \\
\text { conocer de manera clara } \\
\text { cuál será el producto final } \\
\text { (audiovisual, presentación } \\
\text { Power Point...). }\end{array}$ \\
\hline
\end{tabular}


$\checkmark \quad$ El proceso no permite conocer al usuario cómo debe resolver la tarea propuesta.

$\checkmark \quad$ El proceso de resolución no permite desarrollar la tarea propuesta de una manera eficiente.

\section{Proceso}

\begin{tabular}{|l|ll}
$\checkmark \quad$ El proceso da a conocer cómo & $\checkmark$ & $\begin{array}{l}\text { Cada paso del proceso se } \\
\text { se debe resolver la tarea }\end{array}$ \\
propuesta, pero faltan algunas & & $\begin{array}{l}\text { mayoría de los alumnos } \\
\text { directrices para que sea claro. } \\
\checkmark \quad \text { El proceso permite desarrollar } \\
\text { la tarea de una manera más o } \\
\text { menos efectiva, pero no atiende } \\
\text { al planteamiento deductivo de } \\
\text { la tarea. }\end{array}$ \\
& $\checkmark \begin{array}{l}\text { cuál es el siguiente. } \\
\text { Las estrategias organización y } \\
\text { en el proceso son abundantes }\end{array}$ \\
& $\checkmark \begin{array}{l}\text { y válidas para conseguir los } \\
\text { objetivos propuestos. } \\
\text { El proceso de resolución } \\
\text { presenta un planteamiento } \\
\text { construccionista. }\end{array}$ \\
&
\end{tabular}

\begin{tabular}{|c|c|c|c|c|c|}
\hline$\checkmark$ & $\begin{array}{l}\text { Los recursos } \\
\text { proporcionados no son } \\
\text { suficientes para que los } \\
\text { alumnos logren la tarea. } \\
\text { Los recursos ofrecidos } \\
\text { aportan información } \\
\text { errónea o no relacionada } \\
\text { con la tarea propuesta. }\end{array}$ & $\checkmark$ & $\begin{array}{l}\text { Los recursos tienen cierta } \\
\text { conexión con la tarea y el } \\
\text { proceso presentados, pero } \\
\text { algunos de ellos no aportan } \\
\text { nada nuevo. } \\
\text { Los recursos presentados } \\
\text { proceden únicamente de } \\
\text { Internet. }\end{array}$ & $\begin{array}{l}\checkmark \\
\checkmark\end{array}$ & $\begin{array}{l}\text { Los recursos ofrecidos han } \\
\text { sido valorados y ofrecen } \\
\text { una información clara } \\
\text { y veraz sobre el tema a } \\
\text { investigar. } \\
\text { Los recursos presentados } \\
\text { permiten llevar a cabo } \\
\text { un planteamiento } \\
\text { construccionista. } \\
\text { A la información } \\
\text { procedente de Internet se } \\
\text { suman otras referencias } \\
\text { bibliográficas que permiten } \\
\text { contrastar la información de } \\
\text { la que se hace uso. }\end{array}$ \\
\hline \multicolumn{6}{|c|}{ Evaluación } \\
\hline$\checkmark$ & $\begin{array}{l}\text { No se presentan ni criterios } \\
\text { de evaluación ni de } \\
\text { calificación. } \\
\text { La evaluación propuesta no } \\
\text { guarda una relación directa } \\
\text { con los objetivos de la } \\
\text { webquest. }\end{array}$ & $\checkmark$ & $\begin{array}{l}\text { Los criterios de evaluación y } \\
\text { calificación se describen de } \\
\text { manera incompleta. } \\
\text { Sólo aparecen criterios } \\
\text { cuantitativos o cualitativos. }\end{array}$ & $\checkmark$ & $\begin{array}{l}\text { La evaluación propuesta } \\
\text { presenta criterios } \\
\text { cualitativos y cuantitativos } \\
\text { claramente diferenciados y } \\
\text { definidos. } \\
\text { La evaluación propuesta } \\
\text { hace alusión a algún } \\
\text { instrumento de evaluación } \\
\text { que aporta objetividad al } \\
\text { proceso. }\end{array}$ \\
\hline
\end{tabular}




\begin{tabular}{|c|c|c|c|c|c|}
\hline \multicolumn{6}{|c|}{ Conclusión } \\
\hline$\checkmark$ & $\begin{array}{l}\text { La conclusión presentada es } \\
\text { meramente formal y no se } \\
\text { relaciona con lo tratado en la } \\
\text { webquest. }\end{array}$ & $\checkmark$ & $\begin{array}{l}\text { La conclusión da una visión } \\
\text { general de lo que supone la } \\
\text { realización de la webquest, } \\
\text { pero no invita al usuario a la } \\
\text { reflexión. }\end{array}$ & $\checkmark$ & $\begin{array}{l}\text { La conclusión es clara, } \\
\text { concisa y deja una puerta } \\
\text { abierta a la reflexión. }\end{array}$ \\
\hline \multicolumn{6}{|c|}{ ITEMS DE VALORACIÓN APLICABLES A TODOS LOS APARTADOS } \\
\hline \multicolumn{6}{|c|}{ Ortografía y gramática } \\
\hline & $\begin{array}{l}\text { Se detectan graves errores } \\
\text { ortográficos y gramaticales }\end{array}$ & & $\begin{array}{l}\text { La ortografía es buena, pero } \\
\text { algunas construcciones } \\
\text { gramaticales no son correctas } \\
\text { e inciden al equívoco. }\end{array}$ & & $\begin{array}{l}\text { La ortografía y la } \\
\text { gramática son correctas. }\end{array}$ \\
\hline \multicolumn{6}{|c|}{ Calidad de las imágenes presentadas } \\
\hline$\checkmark$ & $\begin{array}{l}\text { No se presentan ningún } \\
\text { tipo de recurso visual. }\end{array}$ & & $\begin{array}{l}\text { Se presentan imágenes, } \\
\text { pero en algunos casos no } \\
\text { responden a los objetivos de } \\
\text { la webquest. }\end{array}$ & $\checkmark$ & $\begin{array}{l}\text { Las imágenes presentadas } \\
\text { son claras, y se incluyen } \\
\text { imágenes de creación } \\
\text { propia que son clave } \\
\text { para la resolución de la } \\
\text { webquest. }\end{array}$ \\
\hline \multicolumn{6}{|c|}{ Uso ético de la información } \\
\hline $\begin{array}{l}\checkmark \\
\checkmark\end{array}$ & $\begin{array}{l}\text { No se citan las } \\
\text { fuentes usadas para la } \\
\text { formulación o resolución } \\
\text { de la webquest. } \\
\text { No se hace uso de las } \\
\text { citas visuales. }\end{array}$ & $\begin{array}{l}\checkmark \\
\checkmark\end{array}$ & $\begin{array}{l}\text { Aparecen citas textuales, } \\
\text { pero no siguen las } \\
\text { normas APA (American } \\
\text { Psychological Association). } \\
\text { Las citas visuales están } \\
\text { formuladas de manera } \\
\text { incorrecta. }\end{array}$ & $\begin{array}{l}\checkmark \\
\checkmark \\
\checkmark\end{array}$ & $\begin{array}{l}\text { Las posibles citas } \\
\text { textuales son correctas } \\
\text { y cumplen con rigor las } \\
\text { normas APA. } \\
\text { Las citas visuales están } \\
\text { formuladas de manera } \\
\text { acertada para facilitar el } \\
\text { uso de las imágenes a } \\
\text { otros usuarios. }\end{array}$ \\
\hline \multicolumn{4}{|c|}{ PUNTUACIÓN TOTAL } & & 150 \\
\hline
\end{tabular}

